\title{
SLA Based Information Security Metric for Cloud Computing from COBIT 4.1 Framework
}

\author{
MUHAMMAD IMRAN TARIQ ${ }^{1}$, DR. IRFAN UL HAQ ${ }^{2}$, JAVEED IQBAL ${ }^{3}$ \\ ${ }^{1}$ M.Phil Student, Department of Computer Science, The University of Lahore, Lahore, Pakistan \\ ${ }^{2}$ Solution Architect, Bitmatriks Software Solutions, Islamabad, Pakistan \\ ${ }^{3}$ M.Phil Student, Department of Computer Science, The Govt. College University, Faisalabad, Pakistan \\ E-mail: ${ }^{1}$ imrantariqbutt@yahoo.com, ${ }^{2}$ irfan@email.com, ${ }^{3}$ javeedy80pk@yahoo.com
}

\begin{abstract}
Cloud Computing is one of the rapidly adopted technology in the field of Information and Communication Technology (ICT) in which resources (like processor and storage devices) can be rented out and released by the Cloud customer by using the Internet in on-demand basis. Information Security issues in Cloud Computing hold vital importance as the global economy depends upon the secure flow of information within the organization and exchange of information with other organization (private and public Cloud). To measure security in Cloud Computing at each level, Information Security metrics are better tools that help the organization to take good decisions on the base of qualitative and quantitative analysis, performance reports, efficiency and effectiveness of the implemented standard or certification security controls. SLA metrics are mostly used to evaluate performance of the service object but not to measure Information Security risks. These service objects can be further categorized as Hardware, Software, Network, Storage and Help Desk / Service Desk. Each object has its own quality metrics and can be combined to form a complex and compound service. COBIT is IT Governance framework which is widely used in IT industry. It covers several areas of IT Governance. Information Security is the part of this framework and the same part can be used to build SLA based Information Security Metrics in Cloud Computing. To obtain Information Security Metrics particularly for Cloud Computing, a criteria have been developed and Information Security Metrics are developed accordingly to facilitate both Cloud Customers and Cloud Service Providers.
\end{abstract}

Keywords: Cloud Computing, Information Security, Security Metrics, Service Level Agreement, COBIT.

\section{INTRODUCTION}

Now in days, the customers are demanding new Information Technology Services and the Cloud Computing is the new innovation in the paradigm of Information Technology that offers more services than traditional computing. Although, it has several advantages over traditional computing but it has several disadvantages i.e. loss of governance, malicious insider, backup and recovery, privacy, security, different data protection laws in different countries and etc. Among these risks, the Information Security is very critical issues and it needs more attention of the Cloud venders to secure their customer's data. Due to these challenges, the Cloud Customers are required to build a mechanism to measure and improve the security of their their Cloud system. There are several ways to improve the security of the Cloud system like continuous monitoring of system, improvement in the system according to monitor activities and improve the Information Security in the Cloud [1].

The Cloud Service Provider (CSP) always provides a guarantee to their Customers that their data will be saved and there is no issue regarding security, privacy of customer data at their part but in real cases, some time, the Cloud Service Providers failed to provide security and privacy in the true sense that Cloud Customer required to maintain its Cloud resources [2]. Moreover, in the 
past, the services of CSPs failed and the Cloud Customer faced great trouble in its finance [3].

Information Security Metrics are the best tools to measure the efficiency in quantitative and qualitative ways of the Cloud Service Provider. The Cloud organizations often used / implement already available traditional computing Information Security Metrics or develop their own.

In Cloud Computing, the resources are delivered to the Cloud Customers as service and therefore, the Cloud organizations are required to implement Information Security Metrics through Service Level Agreement (SLA).

The SLA is a legal document that both organizations signed after deciding the terms and conditions of the agreement. For Cloud Computing, the services that are Cloud organizations are going to render, included in the agreement and in case of violation of agreement from either side, a penalty will be imposed on the accused party [4].

SLA based Information Security Metrics are therefore used to measure the service level between Cloud Service Provider and Cloud Customer. The SLA is mostly used to measure the performance of the Cloud organization than security measurement [5].

During literature review, it is revealed that the several researches have been made in the area of security metrics, cloud computing and SLA. However, the research community did not focus on SLA based information security metrics computing especially for Cloud Computing.

It is also revealed during the literature review of different standards and frameworks for information security and found that COBIT is the best framework to obtain SLA based Information Security Metrics in Cloud Computing.

\section{INFORMATION SECURITY METRICS}

Information Security metrics are quantitative measurement process to evaluate the organization security. Metrics facilitate the organization to take better decisions about various aspects of security like security architecture and efficiency and controls of security operations.

Some authorities create confusion in term Metrics and Measurements but in reality both terms have the same meaning and functionality. NIST SP 800-55 Revision 1 used security measurement term and avoids the term security metrics. The first version of SP 800-55 was "Security Metrics Guide for Information Technology Systems" [6]. According to NIST security measurement is "Security measures facilitate decision making and improve performance and accountability through the collection, analysis, and reporting of relevant performance-related data" [6].

\subsection{Attributes of Metrics}

There are several definitions about the good metrics attributes [8]. He advises that security metrics should be SMART: Specific, Measurable, Attainable, Repeatable, and Time-dependent. Research by Herrmann stated that the ideal metrics should be calculated by a number, cost effective, correct and exact [9].

The other definition of security metrics is Jaquith that metrics are required to be consistent with measurement, inexpensive to gather, contextually specific and expressed as a number [10].

Although, there are several different definitions of security metrics, it may be said that in general, best metrics are likely to have given below characteristics:

- Metrics must have the capability to measure and communicate things in which context they are intended.

- The estimated value of metric not exceed to their cost.

- Measurement method must be low-priced and simple to get good results within time.

- Metrics should be objective and quantifiable. Its means metrics can be derived through accurate values.

- Metrics should have the property to be consistently reproducible by different reviewers.

- Metrics should be able to be tracked over time.

- It should be consistent in what it measures.

\section{SERVICE LEVEL AGREEMENT}

SLA is a legal and contractual document written between Cloud Service Provider (CSP) and Cloud Customer. It is about the service levels offered by the CSP to the customer [13]. There are several advantages of Service Level Agreement but the main advantages is the understanding of the responsibilities of CSP and customer. In SLA, all modalities are defined with the consultation of both parties and before writing SLA, both parties negotiate each term of the SLA and finalize it. 
The SLA defines the term "What" instead of "How" [11]. This thing revealed that the SLA defines what type of services and their level is the customer is expected from the CSP. It also defined both parties responsibilities and expected and unexpected events that can happen to the service.

As we know that, in Cloud environment, the customer transfers his information and data to the CSP and the Cloud Organization does not know about the physical location of its data and information. Now the Cloud organization can use its SLA to assure the security and privacy of its data.

Therefore, it is recommended that while writing SLA, both parties should embrace security and privacy issues starting from performance.

\section{CONTROL OBJECTIVES FOR INFORMATION AND RELATED TECHNOLOGY (COBIT)}

According to ISACA, COBIT is IT governance framework and provide a catalog of control, it supports a tool set that permits organizational managers to fill the gap between organizational technical issues, organization risk and control requirements [12]. It is also known as complete IT governance framework required to be implemented in large scale enterprise.

COBIT act as an organization IT system governance and control development framework and it provides 2 methods:

1. Defining an Information Technology strategy.

2. Third-party management services.

It also offers a maturity model that may employ to determine the maturity of the IT governance processes of an organization.

For users of Cloud Computing,adopting of COBIT framework procedures, the customer shall be able to decide what needs to be done after and before the adoption of the cloud's solution. Moreover, the COBIT also helps the organizations to monitor the value that is obtained through the adoption of Cloud Computing.

The above said maturity model also assist the organization to know IT governance level of maturity, this will facilitate to know whether maturity level is acceptable or not after the adoption of Cloud Computing.

Hence, by using COBIT, organizations can regulate high-quality practices to ensure that IT investment is achieving business targets (ITGI, 2007). In this scenario, COBIT helps organizations to ensure that adoption of Cloud services will bring good values without negotiation. Figure 1 is overall COBIT 4.1 Framework.

To decide, whether an organization has the ability regarding security in Cloud Computing, the organization may try this framework answer questions regarding governance and best practices. Moreover, COBIT used in IT auditing and has the ability to use in combination with other Information Technology relevant frameworks, certifications and standards like ISO 27001 and NIST SP 800-55 Rev.1. In addition to this, it is very best guide in the development of security metrics for Cloud Computing.

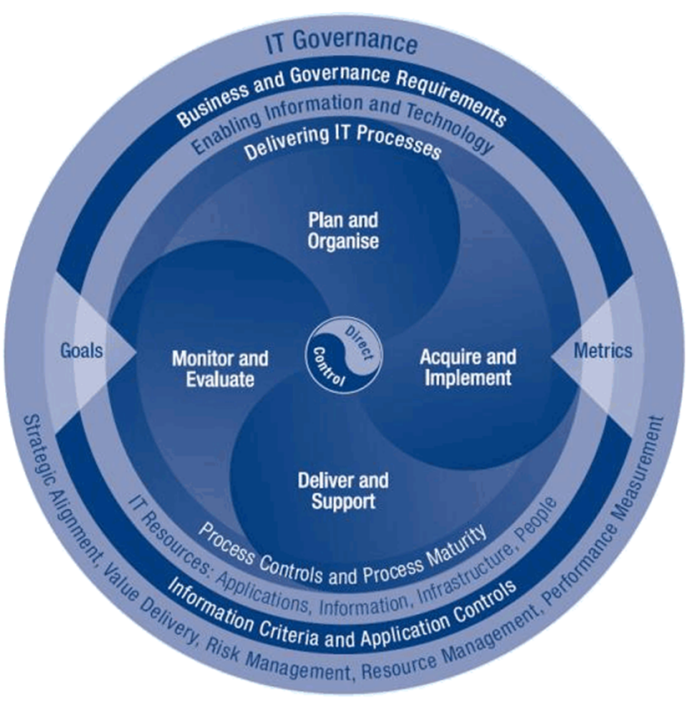

Fig. 1. Overall COBIT 4.1 Frameworks.

5

\section{CRITERIA FOR THE SELECTION OF SLA BASED INFORMATION SECURITY METRICS}

The following criteria are developed to identify manageable, measure-able, the precise number of metrics that are related to Information Security from COBIT framework.

The identified metrics can be included in the SLA and the both Cloud parties can measure their security related issues.

Table 1: Criteria For The Selection Of SLA Based Information Security Metrics From COBIT

\begin{tabular}{|c|l|l|}
\hline $\begin{array}{c}\text { Sr. } \\
\#\end{array}$ & \multicolumn{1}{|c|}{ Criteria } & \multicolumn{1}{|c|}{ Remarks } \\
\hline 1 & $\begin{array}{l}\text { Relevant to } \\
\text { Cloud } \\
\text { Computing? }\end{array}$ & $\begin{array}{l}\text { There are a number of } \\
\text { frameworks and standards } \\
\text { to manage IT infrastructure } \\
\text { and have some time have }\end{array}$ \\
\hline
\end{tabular}


M. I. Tariq et al. / International Journal of Computer Networks and Communications Security, 1 (3), August 2013

\begin{tabular}{|c|c|c|}
\hline & & $\begin{array}{l}\text { little bit portion of cloud } \\
\text { computing. } \\
\text { NIST, COBIT, SANS, ISO } \\
\text { and etc have a number of } \\
\text { guides which can be used } \\
\text { to develop security metrics. } \\
\text { In these guides, every } \\
\text { defined control is not } \\
\text { relevant to cloud } \\
\text { computing. Therefore, to } \\
\text { select relevant processes } \\
\text { for cloud computing, the } \\
\text { said criteria have been } \\
\text { developed and it will help } \\
\text { to select only cloud related } \\
\text { processes for cloud } \\
\text { computing. }\end{array}$ \\
\hline 2 & $\begin{array}{l}\text { Related to } \\
\text { Information } \\
\text { Security? }\end{array}$ & $\begin{array}{l}\text { Framework and standard } \\
\text { covered and discussed wide } \\
\text { range of IT governance } \\
\text { issues of an organization, } \\
\text { but this project only relates } \\
\text { to information security. } \\
\text { The second criteria will } \\
\text { only pick those processes } \\
\text { which are relevant to } \\
\text { information security. }\end{array}$ \\
\hline 3 & $\begin{array}{l}\text { Applicable } \\
\text { to any or all } \\
\text { of cloud } \\
\text { service } \\
\text { model } \\
\text { (SaaS, } \\
\text { PaaS, IaaS } \\
\text { and XaaS)? }\end{array}$ & $\begin{array}{l}\text { This criteria will check that } \\
\text { whether the selected } \\
\text { control is applicable to any } \\
\text { or all of the cloud service } \\
\text { model. } \\
\text { Some controls are partially } \\
\text { relevant to information } \\
\text { security for cloud } \\
\text { computing and not fully } \\
\text { satisfy the criteria. }\end{array}$ \\
\hline 4 & $\begin{array}{l}\text { Fulfill the } \\
\text { criteria to } \\
\text { be selected } \\
\text { as control? }\end{array}$ & $\begin{array}{l}\text { Selection of a control is a } \\
\text { very critical process and } \\
\text { during the selection of } \\
\text { processes, if process fulfills } \\
\text { the requirements of its } \\
\text { characteristics then it will } \\
\text { be selected otherwise drop. } \\
\text { For example, if the } \\
\text { processes cost is too high } \\
\text { then its risk then it will not } \\
\text { selected. }\end{array}$ \\
\hline 5 & $\begin{array}{l}\text { Suitable to } \\
\text { be included } \\
\text { in the SLA } \\
\text { for Cloud? }\end{array}$ & $\begin{array}{l}\text { This is the second last } \\
\text { criteria in which control } \\
\text { suitability will be checked, } \\
\text { every process is not } \\
\text { suitable to be included in } \\
\text { the SLA. Therefore, } \\
\text { processes which are } \\
\text { relevant to SLA will be }\end{array}$ \\
\hline
\end{tabular}

\begin{tabular}{|l|l|l|}
\hline & & selected. \\
\hline \multirow{6}{*}{6} & Related to & $\begin{array}{l}\text { The last criteria is not strict, } \\
\text { here, it will only check that } \\
\text { shether this process is } \\
\text { subject } \\
\text { study? }\end{array}$ \\
$\begin{array}{l}\text { related to subject study or } \\
\text { not? }\end{array}$ \\
\hline
\end{tabular}

The COBIT IT Governance framework has 34 different processes for the governance of IT infrastructure of an organization. Every process has a separate function and in Cloud scenario, all these controls are not applicable as the Cloud Customer data processes on CSP site. The COBIT 4.1 processes are given in Table 2.

Table 2: List Of The COBIT 4.1 Processes

\begin{tabular}{|l|l|}
\hline $\begin{array}{c}\text { Control } \\
\text { ID }\end{array}$ & \multicolumn{1}{|c|}{ Control Name } \\
\hline PO1 & Define a Strategic IT Plan \\
\hline PO2 & Define the Information Architecture \\
\hline PO3 & Determine Technological Direction \\
\hline PO4 & $\begin{array}{l}\text { Define the IT Processes, Organization } \\
\text { and Relationships }\end{array}$ \\
\hline PO5 & Manage the IT Investment \\
\hline PO6 & $\begin{array}{l}\text { Communicate Management Aims and } \\
\text { Direction }\end{array}$ \\
\hline PO7 & Manage IT Human Resources \\
\hline PO8 & Manage Quality \\
\hline PO9 & Assess and Manage IT Risks \\
\hline PO10 & Manage Projects \\
\hline AI1 & Identify Automated Solutions \\
\hline AI2 & $\begin{array}{l}\text { Acquire and Maintain Application } \\
\text { Software }\end{array}$ \\
\hline AI3 & $\begin{array}{l}\text { Acquire and Maintain Technology } \\
\text { Infrastructure }\end{array}$ \\
\hline AI4 & Enable Operation and Use \\
\hline AI5 & Procure IT Resources \\
\hline AI6 & Manage Changes \\
\hline AI7 & $\begin{array}{l}\text { Install and Accredit Solutions and } \\
\text { Changes }\end{array}$ \\
\hline DS1 & Define and Manage Service Level \\
\hline DS2 & Manage Third-party Services \\
\hline DS3 & Manage Performance and Capacity \\
\hline DS4 & Ensure Continuous Service \\
\hline DS5 & Ensure Systems Security \\
\hline DS6 & Identify and Allocate Costs \\
\hline DS7 & Educate and Train Users \\
\hline DS8 & Manage Service Desk and Incidents \\
\hline DS9 & Manage the Configuration \\
\hline DS10 & Manage Problems \\
\hline DS11 & Manage Data \\
\hline DS12 & Manage the Physical Environment \\
\hline DS13 & Manage Operations \\
\hline ME1 & Monitor and Evaluate IT Performance \\
\hline
\end{tabular}


M. I. Tariq et al. / International Journal of Computer Networks and Communications Security, 1 (3), August 2013

\begin{tabular}{|l|l|}
\hline ME2 & Monitor and Evaluate Internal Control \\
\hline ME3 & $\begin{array}{l}\text { Ensure Compliance With External } \\
\text { Requirements }\end{array}$ \\
\hline ME4 & Provide IT Governance \\
\hline
\end{tabular}

To obtain Information Security Metrics, the Cloud organization initially has to select the relevant processes from the COBIT framework. Therefore, the criteria made in Table 1 apply on COBIT 4.1 framework and each process of the said framework is evaluated according to the criteria. The Table 3 shows the implementation of the criteria.

Table 3: SELECTION OF SECURITY PROCESSES FOR CLOUD SLA FROM COBIT 4.1 FRAMEWORK

\begin{tabular}{|c|c|c|c|c|c|c|}
\hline \multirow{2}{*}{$\begin{array}{c}\text { Control } \\
\text { ID }\end{array}$} & \multicolumn{6}{|c|}{$\begin{array}{c}\text { Metrics selection criteria Serial } \\
\text { Number }\end{array}$} \\
\hline & 1 & 2 & 3 & 4 & 5 & 6 \\
\hline PO1 & $\mathrm{No}$ & $\mathrm{No}$ & No & No & No & No \\
\hline PO2 & Yes & Yes & Yes & Yes & No & No \\
\hline PO3 & Yes & Yes & Yes & Yes & $\mathrm{No}$ & $\mathrm{No}$ \\
\hline PO4 & Yes & Yes & Yes & Yes & No & Yes \\
\hline PO5 & Yes & Yes & Yes & Yes & No & Yes \\
\hline PO6 & Yes & Yes & Yes & No & $\mathrm{No}$ & No \\
\hline PO7 & Yes & Yes & Yes & No & No & No \\
\hline PO8 & Yes & Yes & Yes & Yes & No & Yes \\
\hline PO9 & Yes & Yes & Yes & Yes & Yes & Yes \\
\hline PO10 & No & No & No & No & No & No \\
\hline AI1 & Yes & Yes & Yes & Yes & No & Yes \\
\hline $\mathrm{AI} 2$ & Yes & Yes & Yes & Yes & Yes & Yes \\
\hline AI3 & Yes & Yes & Yes & Yes & Yes & Yes \\
\hline AI4 & Yes & Yes & Yes & Yes & Yes & Yes \\
\hline AI5 & Yes & Yes & Yes & Yes & No & Yes \\
\hline AI6 & Yes & Yes & Yes & Yes & $\mathrm{No}$ & Yes \\
\hline AI7 & Yes & Yes & Yes & Yes & No & Yes \\
\hline DS1 & Yes & Yes & Yes & Yes & No & No \\
\hline DS2 & Yes & Yes & Yes & Yes & Yes & Yes \\
\hline DS3 & Yes & Yes & Yes & Yes & Yes & Yes \\
\hline DS4 & Yes & Yes & Yes & Yes & Yes & Yes \\
\hline DS5 & Yes & Yes & Yes & Yes & Yes & Yes \\
\hline DS6 & No & No & No & No & No & No \\
\hline DS7 & Yes & No & No & No & No & No \\
\hline DS8 & Yes & Yes & Yes & Yes & Yes & Yes \\
\hline DS9 & Yes & Yes & Yes & Yes & Yes & Yes \\
\hline DS10 & Yes & Yes & Yes & Yes & Yes & Yes \\
\hline DS11 & Yes & Yes & Yes & Yes & Yes & Yes \\
\hline DS12 & Yes & Yes & Yes & Yes & No & No \\
\hline DS13 & Yes & Yes & Yes & Yes & Yes & Yes \\
\hline ME1 & Yes & Yes & Yes & Yes & Yes & Yes \\
\hline ME2 & Yes & Yes & Yes & Yes & Yes & Yes \\
\hline ME3 & Yes & Yes & Yes & Yes & Yes & Yes \\
\hline ME4 & Yes & Yes & No & No & No & No \\
\hline
\end{tabular}

After applying the criteria, we found that only 14 processes met process selection criteria and theses processes are given as under in Table 4.

Table 4: COBIT 4.1 Processes That Met Criteria

\begin{tabular}{|l|l|}
\hline $\begin{array}{c}\text { Control } \\
\text { ID }\end{array}$ & \multicolumn{1}{c|}{ Control Name } \\
\hline PO9 & Assess and Manage IT Risks \\
\hline AI2 & $\begin{array}{l}\text { Acquire and Maintain Application } \\
\text { Software }\end{array}$ \\
\hline AI3 & $\begin{array}{l}\text { Acquire and Maintain Technology } \\
\text { Infrastructure }\end{array}$ \\
\hline AI4 & Enable Operation and Use \\
\hline DS2 & Manage Third-party Services \\
\hline DS3 & Manage Performance and Capacity \\
\hline DS4 & Ensure Continuous Service \\
\hline DS5 & Ensure Systems Security \\
\hline DS8 & Manage Service Desk and Incidents \\
\hline DS9 & Manage the Configuration \\
\hline DS10 & Manage Problems \\
\hline DS11 & Manage Data \\
\hline ME1 & Monitor and Evaluate IT Performance \\
\hline ME2 & Monitor and Evaluate Internal Control \\
\hline ME3 & $\begin{array}{l}\text { Ensure Compliance With External } \\
\text { Requirements }\end{array}$ \\
\hline
\end{tabular}

It is worthwhile to mention here that every process of the COBIT framework has a number of metrics. The total number of metrics in COBIT framework for IT Governance is 340 and the domain Deliver and Support (DS) has 120 metrics.

The Table 5 describes detailed about COBIT processes and its respective number of metrics.

\section{Table 5: COBIT 4.1 Processes and Metrics}

\begin{tabular}{|c|c|c|}
\hline Process & Metrics & Percentage \\
\hline Plan and Organize (PO) & 103 & $30 \%$ \\
\hline $\begin{array}{l}\text { Acquire and Implement } \\
\text { (AI) }\end{array}$ & 73 & $22 \%$ \\
\hline $\begin{array}{l}\text { Deliver and Support } \\
\text { (DS) }\end{array}$ & 120 & $35 \%$ \\
\hline $\begin{array}{l}\text { Monitor and Evaluate } \\
\text { (ME) }\end{array}$ & 44 & $13 \%$ \\
\hline Total & 340 & \\
\hline
\end{tabular}

The COBIT framework numbers of metrics in percentage are shown in Figure 2. 


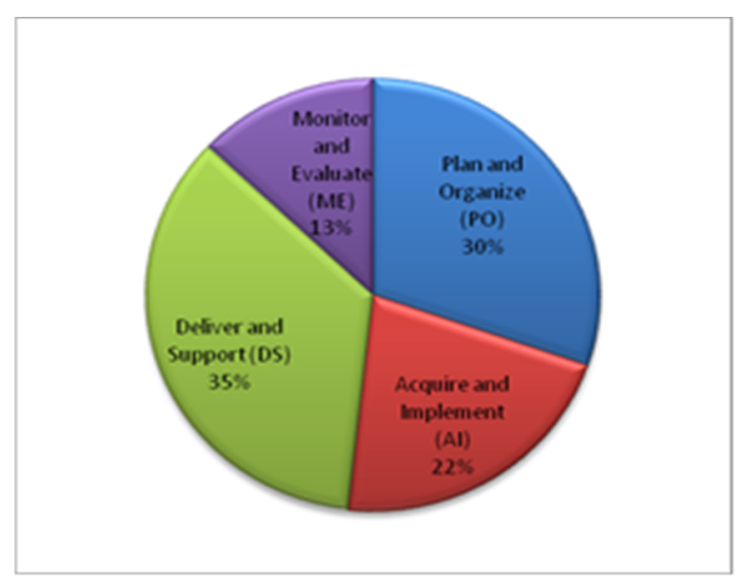

Fig. 2. Distribution Of Metrics In The Four Domains Of COBIT Framework.

These metrics are very huge and it is hard for an organization to maintain their data plus these metrics are not cost effective for Cloud Customers. Moreover, these all metrics are not relevant to Cloud Computing as our results show that in Deliver and Support (DS) domain only DS2 to DS5 and DS8 to DS11 are relevant processes for Cloud SLA.

The number of identified metrics from COBIT framework processes for Cloud Computing according to criteria are as given in Table 6.

Table 6: Number Of Identified Metrics

\begin{tabular}{|c|c|c|}
\hline Process & Metrics & Percentage \\
\hline Plan and Organize (PO) & 12 & $4 \%$ \\
\hline $\begin{array}{l}\text { Acquire and Implement } \\
\text { (AI) }\end{array}$ & 29 & $9 \%$ \\
\hline $\begin{array}{l}\text { Deliver and Support } \\
\text { (DS) }\end{array}$ & 77 & $23 \%$ \\
\hline $\begin{array}{l}\text { Monitor and Evaluate } \\
(\mathrm{ME})\end{array}$ & 32 & $9 \%$ \\
\hline Total & 150 & $44 \%$ \\
\hline
\end{tabular}

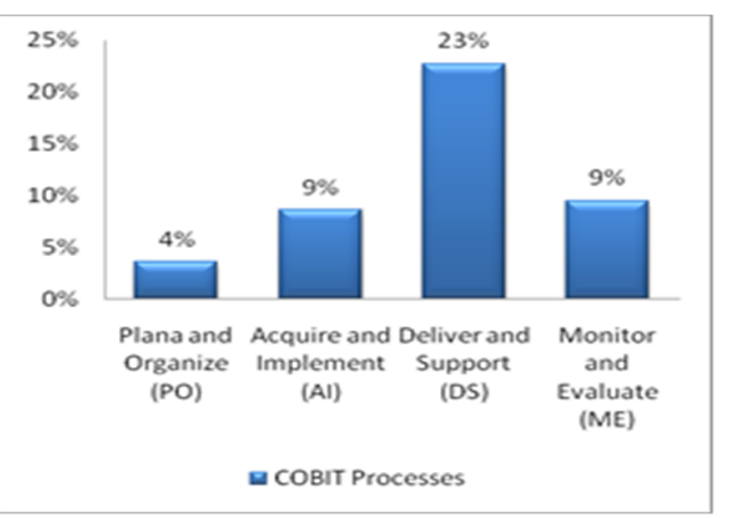

Fig. 3. Effectiveness of COBIT Framework Process For Cloud Computing
The Figure 3 shows that it has only 4\% processes for Cloud Computing, Acquire and Implement (AI) and Monitor and Evaluate domains / process have 9\% metrics and the Deliver and Support domain / process has 23\% metrics for Cloud Computing.

If we consolidate these four domains / process metrics then we come to know that COBIT framework $44 \%$ metrics can be used in Cloud Computing.

Every Cloud organization has its own requirements and implementation of metrics are depends up the type of Cloud deployment model and Service Model. Furthermore, the Cloud organizations some time deploy Hybrid Cloud deployment model and obtain partial services from CSP. The use of metrics for security and privacy vary organization to organization. While selecting metrics for security, the organizations have to keep its mind about the characteristics of the good metrics. There are various characteristics of good metrics and as per our research, the Jaquith metrics are sufficient for the selection of good metrics [9].

The results shown in Table 4 depicts that the organizations who are intended to maintain their privacy and security of data may implement COBIT 4.1 framework in their organizations and the identified process are relevant to security and privacy domains. These domains have sufficient metrics and Cloud organizations have to implement the metrics that fulfil their needs and requirements according to Cloud services they rendered from CSPs.

\section{CONCLUSION AND FUTURE WORK}

Cloud Computing is a very growing technology due to its elastic and on demand services to Cloud Customers. It has several advantages over traditional computing but it is not as such mature technology which provide $100 \%$ security and privacy guarantees. Due to new technology, Cloud potential customers are facing some roadblocks in its deployment and security is the top most security risk for Cloud organizations.

To overcome these security issues, the Cloud organizations have to implement Information Security standards, guides, certifications and frameworks to protect data. COBIT is the world wide acceptable IT Governance framework and it has Information Security domains that are sufficient to provide security to Cloud organizations. The COBIT identified processes for the development of Information Security metrics can be used in SLA. The said framework has 340 metrics and these are partially related to the Cloud technology. The criteria made in this research, identified only those 
processes that are relevant to Cloud technology and easy to implement in the Cloud environment to protect Cloud organization data. We recommend to Cloud organizations to select only those metrics which fulfill their organization's needs and satisfy the criteria of good metrics. The selected metrics should be quantitative and produce the results numeric figure. Moreover, the selected metrics should be cost effective and easy to measure.

The selected metrics from identified processes should be become the part of the SLA and the CSP should bound to provide requisite information relating to metrics to Cloud Customers.

The future plan is to identify SLA based information security metrics from ISO / IEC 27001:2005 certification and NIST SP 800-53 Rev.4 standard. A criteria will be made to know that up to what level of security these standards and certifications are provided to Cloud Customers.

\section{REFERENCES}

[1] Tariq, Muhammad Imran, "Towards Information Security Metrics Framework for Cloud Computing." International Journal of Cloud Computing and Services Science (IJCLOSER), 2012, pp. 209-217.

[2] Takabi, Hassan, James BD Joshi, and GailJoon Ahn, "Security and privacy challenges in cloud computing environments", Security \& Privacy, IEEE, 2010, pp. 24-31.

[3] Blate, Alex, and Kevin Jeffay. "Gini in A Bottle: A Case Study of Pareto's Principle in the Wild." International Journal of Computer Networks and Communications Security 1 (2013).

[4] T.S. Kandukuri, Balachandra Reddy, V. Ramakrishna Paturi, and Atanu Rakshi, "Cloud security issues", In Services Computing, 2009. SCC'09. IEEE International Conference, 2009, pp. 517-520.

[5] Paschke, Adrian, and Elisabeth SchnappingerGerull, "A Categorization Scheme for SLA Metrics" Service Oriented Electronic Commerce, 2006, pp. 25-40.

[6] Swanson, M., Bartol, N., Sabato, J., Hash, J., Graffo, L., "Security metrics guide for information technology systems (NIST SP 800-55)", National Institute of Standards and Technology, 2003.

[7] Nelson, C., "Security Metrics: An Overview", ISSA Journal, 2010, pp.12-18.
[8] Jelen, George, "SSE-CMM security metrics", In NIST and CSSPAB Workshop, 2000.

[9] Herrmann, Debra S., "Complete guide to security and privacy metrics: measuring regulatory compliance, operational resilience, and ROI", CRC Press, 2007.

[10] Jaquith, Andrew, "Security metrics: replacing fear, uncertainty, and doubt”, Upper Saddle River: Addison-Wesley, 2007.

[11]De Chaves, Shirlei Aparecida, Carlos Becker Westphall, and Flavio Rodrigo Lamin, "SLA perspective in security management for cloud computing" In Networking and Services (ICNS), 2010 Sixth International Conference, IEEE, 2010, pp. 212-217.

[12] Catteddu, Daniele. "Cloud Computing: benefits, risks and recommendations for information security", Springer Berlin Heidelberg, 2010.

[13]Ul Haq, Irfan, Altaf Huqqani, and Erich Schikuta, "Aggregating hierarchical service level agreements in business value networks" In Business Process Management, Springer Berlin Heidelberg, 2009, pp. 176-192. 